\title{
Acta
Biochimica
Polonica
}

Vol. 41 No. 1/1994

QUARTERLY

\section{The dependence of electrophoretic and spectroscopic properties of the pyruvate dehydrogenase complex on mono- and divalent ions*}

\author{
Tadeusz Pawelczyk $^{\mathrm{a}^{* *}}$, Richard A. Easom ${ }^{\mathrm{b}}$ and Merle S. Olson ${ }^{\mathrm{b}}$ \\ ${ }^{a}$ Faculty of Biotechnology, University of Gdanisk and Medical Academy Gdańsk, M. Curie-Sktodowskiej \\ 3B, 80-210 Gdanisk, Poland ${ }^{b}$ Department of Biochemistry, University of Texas Health Science Center, \\ San Antonio, Texas 78284-7760, U.S.A.
}

Received 8 November, 1993

Key words: pyruvate dehydrogenase complex, structure, ions, UV spectroscopy, kidney

\begin{abstract}
The effects of various mono- and divalent ions on the pyruvate dehydrogenase complex (PDC) were investigated. To determine the radius of PDC under various conditions a two-dimensional agarose gel electrophoresis technique was used. The radius of PDC cross-linked with glutaraldehyde at ionic strength $0.04 \mathrm{M}$ was calculated to be $22.0 \pm 0.1 \mathrm{~nm}$. The presence of $\mathrm{K}^{+}, \mathrm{Na}^{+}$or $\mathrm{HPO}_{4}{ }^{-}$prevented changes in electromobility and of the calculated radius of PDC induced by alteration in ionic strength.

The fluorescence emission spectra of PDC depended on the ionic strength and monovalent cations. The fluorescence intensity of PDC increased in the presence of $80 \mathrm{mM} \mathrm{K}^{+}$, and decreased in the presence of $80 \mathrm{mM} \mathrm{Na}^{+}$with no shift in the emission maximum wavelength.

Changes in the ionic strength to which PDC was exposed resulted in alteration of the UV absorption spectra in the $230 \mathrm{~nm}$ region. These alterations were prevented by $\mathrm{HPO}_{4}{ }^{2-}$, whereas $\mathrm{Na}^{+}$or $\mathrm{K}^{+}$ions had no effect on the $\mathrm{UV}$ absorption spectrum of PDC.
\end{abstract}

The pyruvate dehydrogenase complex occupies a key position in intermediary metabolism. It links glycolysis with other metabolic pathways such as ketogenesis and the tricarboxylic acid cycle. Moreover, because of its location this enzyme complex is an ideal candidate to regulate not only the input of substrate into the tricarboxylic acid cycle but also the flow of carbon in such metabolic processes as gluconeogenesis or lipogenesis. As a conse- quence, the activity of this enzyme complex is finely regulated both by feedback inhibition and reversible phosphorylation.

$\mathrm{PDC}^{1}$ is an example of an organized multienzyme system, a knowledge of whose structure and function has wide implication for understanding of complex protein assembly and function. The mammalian PDC consists of three catalytic components, pyruvate dehydrogenase (E1), lipoamide transacetylase (E2),

T.P.-Supported by an AMG grant W-136; R.A.E.-Supported by an NIH cardiovascular science postdoctoral training grant, HL-07305; M.S.O.-Supported by a grant from the NIH, HL-24654.

**The correspondence and requests for reprints should be addressed to: Tadeusz Pawleczyk, Ph.D., Department of Clinical Biochemistry, Medical Academy Gdańsk, Debinki 7, 80-211 Gdańsk, Poland

${ }^{1}$ Abbreviations used: PDC, pyruvate dehydrogenase complex; $\mathrm{PDH}$, pyruvate dehydrogenase; T3, bacteriophage T3; SBMV, southern bean mosaic virus; TBSV, tomato bushy stunt virus; $\mu_{0}$, free mobility; $I$, ionic strength; $\mathrm{R}$, radius. 
lipoamide dehydrogenase (E3), and two regulatory components, PDH kinase and PDH phosphatase [1]. The E2 component constitutes a core assembly to which the other enzymatic components are bound by noncovalent bonds [2], it consists of 60 copies of E2 arranged into a pentagonal dodecahedral structure [2-4]. The E2 core also contains about six molecules of protein $X[5,6]$ and about three molecules of PDH kinase which are tightly bound to E2 [7]. Immunological studies and evidences obtained from limited proteolysis indicate that, in the bovine kidney PDC, protein X contributes to the binding and function of E3 component [4]. The E2 core binds $20 \mathrm{E} 1$ units, each consisting of a tetramer of two nonidentical subunits, and 12 copies of E3 arranged in six homodimers [8, 9]. The PDH phosphatase, consisting of two nonidentical subunits, reversibly associates with the core [10]. The total relative molecular mass of the bovine kidney pyruvate dehydrogenase complex is approximately $7 \times 10^{6}$ [1]. In an electron micrograph the enzyme complex appears as a structure having a gross diameter of about $21 \mathrm{~nm}$ [11].

Stabilization of such a quaternary structure involves various interactions such as electrostatic, hydrogen bonding, van der Waals, hydrophobic and conformational tension. Thus, changes in the magnitude of any of these contributing interactions may have a substantial effect on the catalytic properties of the enzyme complex. In previous reports it was demonstrated that the activity of PDC was affected by a number of mono- and divalent ions, as well as by changes in ionic strength [12, 13]. In addition, the activity of each enzymatic component of PDC was altered to a different extend by $\mathrm{K}^{+}$, $\mathrm{Na}^{+}, \mathrm{Cl}^{-}, \mathrm{HPO}_{4}{ }^{2-}$ and $\mathrm{HCO}_{3}{ }^{-}$ions $[14,15]$. These ions can influence the activity of $\mathrm{PDC}$ by changing the interactions between substrate and enzyme, or by altering the structure of the enzyme complex. From this perspective it seemed important to determine to what extent the structure of PDC is altered by changes in ionic strength and the presence of ions.

In the present study it has been shown that the ionic strength and $\mathrm{K}^{+}, \mathrm{Na}^{+}, \mathrm{Cl}^{-}, \mathrm{HPO}_{4}{ }^{2-}$ and $\mathrm{HCO}_{3}{ }^{-}$ions affect the electrophoretic and spectroscopic properties of the pyruvate dehydrogenase complex.

\section{EXPERIMENTAL PROCEDURES}

Materials. Bovine serum albumin, Hepes, Tris, Mops, imidazole and glutaraldehyde (EM grade) were obtained from Sigma Chemical Co. (St. Louis, MO, U.S.A.). Seakem LE agarose (underivatized) and SeaPlaque agarose (hydroxyethylated) were received from the Marine Colloids Division of the FMC Corporation (Rockland, ME, U.S.A.). The southern bean mosaic virus, tomato bushy stunt virus, bacteriophage $\mathrm{T} 3$ were a gift from Dr. T.J. Morris. Highly purified preparations of the pig kidney cortex pyruvate dehydrogenase complex (11$14 \mu \mathrm{mol} / \mathrm{min}$ per $\mathrm{mg}$ protein) were prepared as previously described [12]. All other chemicals were of the purest grade commercially available.

Methods. The analysis of the effect of ionic strength and different ions on PDC was performed using two-dimensional agarose gel electrophoresis. PDC $(10 \mathrm{mg} / \mathrm{ml})$ was incubated for $15 \mathrm{~min}$ in Tris/Hepes buffer, $\mathrm{pH} 7.8$, at $0^{\circ} \mathrm{C}$ and at the ionic strength and ions concentrations indicated in the Figure legends. Following incubation for $1 \mathrm{~min}$ at $25^{\circ} \mathrm{C}, \mathrm{PDC}$ was fixed by addition of $10 \mathrm{vol}$. of glutaraldehyde (final concentration $0.35 \%$ ). After $15 \mathrm{~min}$, the fixation reaction was quenched by the addition of Tris buffer, $\mathrm{pH} 7.4$ to a final concentration of $70 \mathrm{mM}$ and samples were subjected to twodimensional agarose gel electrophoresis as described by Easom $e t$ al. [16]. The electrophoresis was performed in a large frame appropriate to embed four first-dimensional gels within a single second-dimension slab [17].

Electrophoresis was first conducted through a low concentration $(0.15 \%$ Seakem LE) agarose gel that had minimal sieving. Thus, particles were separated in this dimension by charge alone. The electrical field was then rotated by $90^{\circ}$ such that the particles were driven into a higher concentration second-dimension gel (2.6\% SeaPlaque agarose) designated to give optimal resolution of PDC from marker particles. Electrophoresis was performed at 2 $\mathrm{V} / \mathrm{cm}$ for $5.5 \mathrm{~h}$ in the first dimension and for 23 $h$ in the second dimension. Buffer was circulated over the gel at $120 \mathrm{ml} / \mathrm{min}$ commencing $30 \mathrm{~min}$ after electrophoresis was started. 
The radius of PDC was determined by measuring the angle $(\theta)$ between the direction of the first-dimension and the straight line (size line) drawn from the origin of electrophoresis to the band of PDC. Particles of the same radius fall on the same size line. The distance moved by the particle from the origin along a size line is an increasing function of free mobility $\left(\mu_{0}\right)$ [17]. The size of the particle can be determined accurately by using markers of which the radii are known. The radii of the markers used were: $30.1 \mathrm{~nm}$ (T3) [18], $17.0 \mathrm{~nm}$ (TBSV) [19], $14.5 \mathrm{~nm}$ (SBMV) [20].

Fluorescence emission spectra were recorded using an SLM-Aminco SPF-500C spectrofluorimeter. The measurements were performed on $40 \mu \mathrm{g}$ of pyruvate dehydrogenase complex in 2 $\mathrm{ml}$ of Tris/Hepes, $1 \mathrm{mM} \mathrm{MgCl} 2 \mathrm{pH} 7.8$ with additions as indicated in Figure legends. The temperature was held constant with a circulating water bath at $25^{\circ} \mathrm{C}$. The sample was excited at $280 \mathrm{~nm}$ and the emission spectra recorded between 300 and $400 \mathrm{~nm}$.

UV spectra were measured using a Shimadzu UV-260 spectrophotometer at $25^{\circ} \mathrm{C}$ with $80 \mu \mathrm{g}$ of PDC in $1 \mathrm{ml}$ of Tris/Hepes, pH 7.8, $1.0 \mathrm{mM}$ $\mathrm{MgCl}_{2}$ with additions as indicated in the Figure legends.

All spectra were corrected for the contribution of solvent.

Ionic strength of the PDC solutions used was standardized to the required value by varying concentration of the buffer. Estimation of the concentrations of conjugate base and conjugate acid for all buffers were calculated from the Henderson-Hasselbalch equation. Ionic strength of the solutions was calculated based on concentration of the ionic forms of all additions. Protein concentrations was estimated by the biuret procedure [21] using bovine serum albumin as a standard.

\section{RESULTS}

Previous reports have shown that the activity of PDC and its components is affected by a number of mono- and divalent ions and changes in ionic strength [12-15]. In the present study we used a newly developed two-dimensional agarose gel electrophoresis technique to investigate the effect of these ions on the conformation of PDC. To determine the radius of
PDC under various conditions, the enzyme complex, together with the size markers, was subjected to two-dimensional agarose gel electrophoresis. The size line for PDC (see methods) is the dashed line in Fig. 1A. By use of the $R(\theta)$ relationship determined from the position of the markers in Fig. 1A, a hydrated R of 22.0 $\pm 0.1 \mathrm{~nm}$ was calculated for the PDC from porcine kidney cortex cross-linked with glutaraldehyde after incubation at $0.04 \mathrm{M}$ ionic strength. The R of the PDC from kidney medulla was the same as that of PDC from the cortex (not shown). The smaller spots to the left of the major 1, 2, 3 and 4 spots in Fig.1 were formed by dimers of PDC. This conclusion was derived from an electron micrograph of particles eluted from these spots [16]. The spots most to the left of major PDC spots on Fig. 1 A, B and D were found to be a trimer. To determine whether multimerization of PDC was caused by a crosslinking process, the cross-linking was performed at $\mathrm{PDC}$ concentration ranging from 120 to $800 \mu \mathrm{g} / \mathrm{ml}$. The percentage of PDC in monomers, dimers and trimers was not altered significantly by the alteration of protein concentration (not shown). Based on this observation we conclude that the multimers existed prior to cross-linking.

The mobility of PDC cross-linked at high ionic strength $(I=0.15 \mathrm{M})$ in the first dimension was decreased compared to that of PDC fixed at low ionic strength $(I=0.04 \mathrm{M})$ (Fig. 1B), indicating a reduced electronegative surface charge. Moreover, an increase in the ionic strength from 0.04 to $0.15 \mathrm{M}$ during fixation caused a decrease in the size of PDC by a marginal but reproducible amount, as demonstrated by displacement of the PDC spot to the right of the size line drawn through the center of the spots formed by PDC cross-linked in low ionic strength media (Fig. 1B). Electrophoretic properties of the enzyme complex fixed at 0.15 $\mathrm{M}$ ionic strength in the presence of $100 \mathrm{mM} \mathrm{K}^{+}$ were similar to those of PDC fixed at low ionic strength (Fig. 1D). The presence of $\mathrm{K}^{+}$ions at low concentration $(20 \mathrm{mM})$ did not affect the electrophoretic properties of PDC fixed at high ionic strength (Fig. 1C). This suggests that $\mathrm{K}^{+}$ at $100 \mathrm{mM}$ concentration prevented the induction by high ionic strength conformational changes. The presence of $\mathrm{Cl}^{-}$or $\mathrm{KHCO}_{3}$ or $\mathrm{NaCl}$ at concentration of $40 \mathrm{mM}$ did not change the electrophoretic characteristics of PDC fixed 


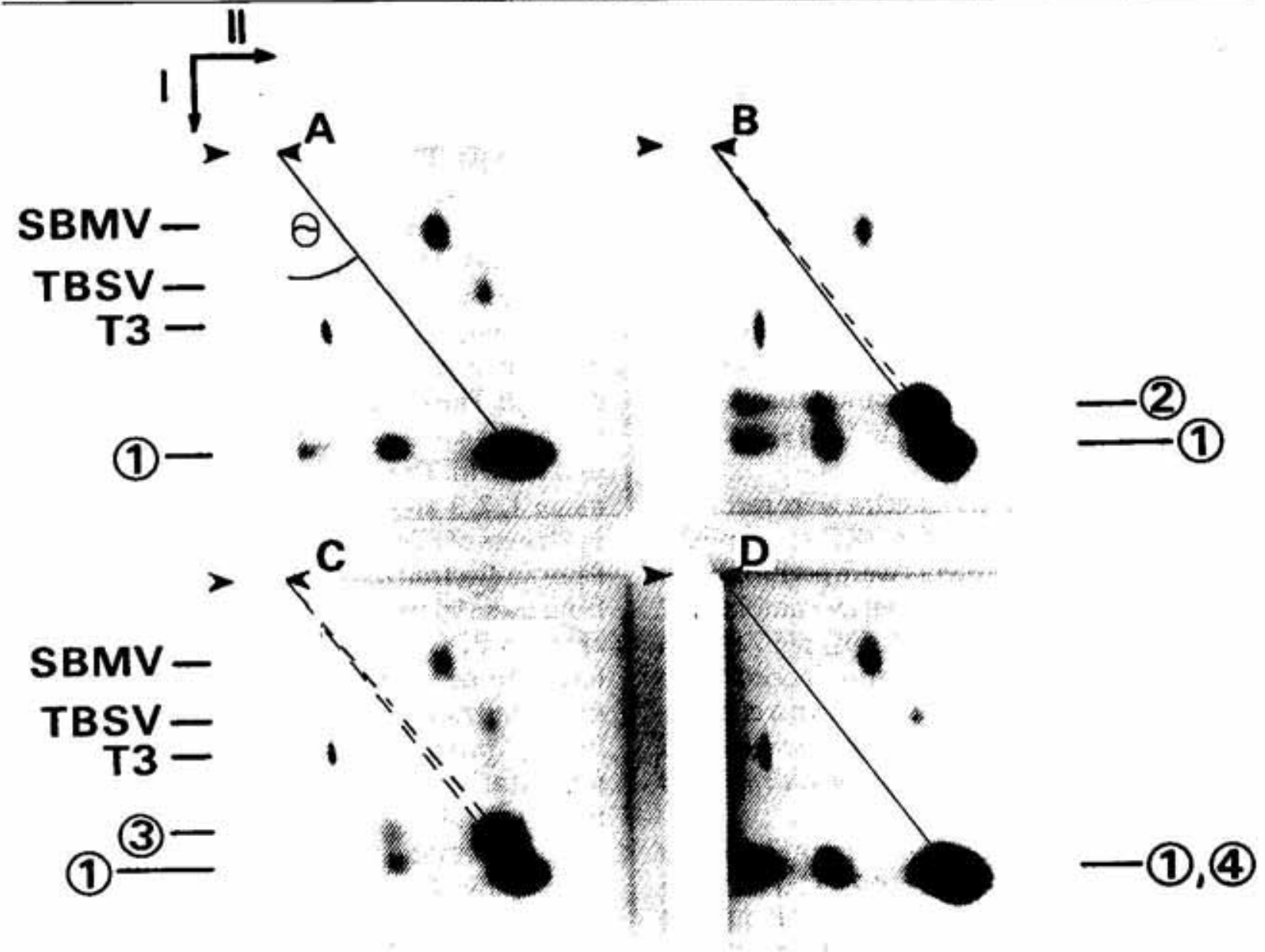

Fig. 1. Two-dimensional gel electrophoresis of the pyruvate dehydrogenase complex cross-linked at different ionic strength.

PDC samples were incubated and cross-linked as described in Experimental Procedures at $I=0.04 \mathrm{M}(1), I=0.15 \mathrm{M}(2)$, $I=0.15 \mathrm{M}$ and the presence of $20 \mathrm{mM} \mathrm{K}^{+}(3), I=0.15 \mathrm{M}$ and the presence of $100 \mathrm{mM} \mathrm{K}^{+}$(4). The ionic strength was adjusted by varying the concentration of Tris/Hepes buffer.The arrows indicate the directions of the first (I) and the second (II) electrophoresis. The arrowheads indicate the origins of the electrophoresis. The solid and dashed lines are the size lines for PDC fixed at $0.04 \mathrm{M}(1)$ and $0.15 \mathrm{M}(2)$ ionic strength, respectively. SBMV, TBSV and T3 are size markers.

at high ionic strength $I=0.15 \mathrm{M}$ (Fig. 2). In contrast, PDC fixed at $0.15 \mathrm{M}$ ionic strength in the presence of $40 \mathrm{mM} \mathrm{HPO}_{4}^{2-}$ had electrophoretic characteristics similar to those of PDC - fixed at low ionic strength (Fig. 3D), suggesting that $\mathrm{HPO}_{4}{ }^{2-}$ prevented the conformational changes induced by high ionic strength.

The fluorescence emission spectra of PDC excited at $280 \mathrm{~nm}$ are shown on Fig. 4. The emission intensity of PDC depended on the ionic strength and the presence of monovalent cations. Increasing the ionic strength to which the enzyme complex was exposed resulted in an increase in the emission intensity and a small red shift of the emission maximum wavelength. At $0.16 \mathrm{M}$ ionic strength the maximum emission of PDC was found at $338 \mathrm{~nm}$. The emission spectrum resulting from excitation of
$\mathrm{PDC}$ at $0.04 \mathrm{M}$ ionic strength shows the maximum at $334 \mathrm{~nm}$ (Fig. 4). The fluorescence intensity of PDC increased in the presence of 80 $\mathrm{mM} \mathrm{K}^{+}$, and decreased in the presence of 80 $\mathrm{mM} \mathrm{Na}{ }^{+}$with no shift in the emission maximum wavelength (Fig. 5 ).

Changes in the ionic strength to which PDC was exposed resulted in alteration of the absorption spectra in the $230 \mathrm{~nm}$ region. The spectrum of PDC obtained at ionic strength of 0.04 M exhibited a peak centered at $228 \mathrm{~nm}$ (Fig. 6). At $0.16 \mathrm{M}$ ionic strength the PDC absorption spectrum showed much smaller peak centered at $234 \mathrm{~nm}$. Addition of $\mathrm{Na}^{+}(80 \mathrm{mM})$ at ionic strength of $0.16 \mathrm{M}$ had no effect on the UV absorption spectrum of PDC (Fig. 6). Similarly $\mathrm{K}^{+}$ions alone had no effect (Fig. 7). When the enzyme complex was exposed to $0.16 \mathrm{M}$ ionic 


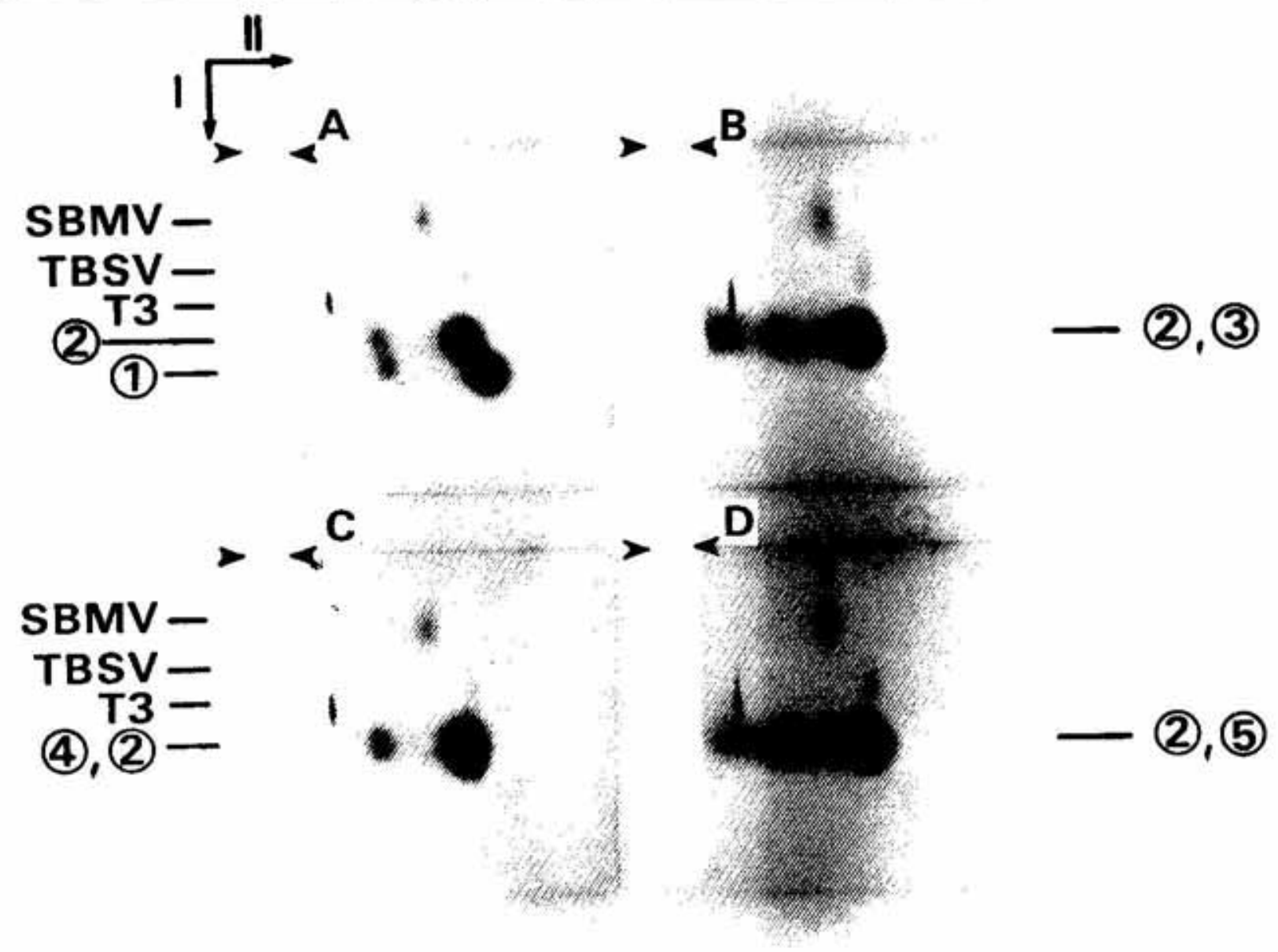

Fig. 2. The effect of monovalent ions on the charge of PDC.

PDC was incubated prior to fixing at $I=0.04 \mathrm{M}(1), I=0.15 \mathrm{M}(2), I=0.15 \mathrm{M}$ and $40 \mathrm{mM} \mathrm{Cl}^{-}(3), I=0.15 \mathrm{M}$ and $40 \mathrm{mM}$ $\mathrm{KHCO}_{3}(4), I=0.15 \mathrm{M}$ and $40 \mathrm{mM} \mathrm{NaCl}(5)$. The arrowheads indicate the origins of the electrophoresis.

strength in the presence of $40 \mathrm{mM} \mathrm{HPO}_{4}{ }^{2-}$ the absorption spectrum closely resembled the spectrum taken at $0.04 \mathrm{M}$ ionic strength (Fig. 6). Addition of $\mathrm{K}^{+}(80 \mathrm{mM})$ and to a lesser extent, $\mathrm{Na}^{+}$in the presence of $40 \mathrm{mM} \mathrm{HPO}_{4}{ }^{2-}$ at 0.16 $M$ ionic strength resulted in a higher absorption of PDC in the $230 \mathrm{~nm}$ region, compared to the absorption intensity at $0.04 \mathrm{M}$ ionic strength (Fig. 7).

\section{DISCUSSION}

The radius value $(R=22.0 \mathrm{~nm})$ of $P D C$ from porcine kidney reported in this contribution agrees well with the $R$ value determined by electron microscopy [11]. This indicates, that the sieving on gels during gel electrophoresis can be used to determine the size of hydrated multimolecular complexes. The equipment needed for quantitating sieving is comparatively simple and inexpensive.
The stability of the protein native state is known to be dependent on ionic strength [2224]. The data presented in this report indicate that the radius of the pyruvate dehydrogenase complex undergoes changes during alteration in ionic strength to which the enzyme complex is exposed. The change of the PDC size was also accompanied by a decrease in the apparent electronegative surface charge of the complex. It can be seen in Fig.1B that the mobility in the first dimension of PDC exposed to high ionic strength $I=0.16 \mathrm{M}$ was decreased compared to the mobility of PDC exposed to low ionic strength $I=0.04 \mathrm{M}$, indicating a reduced electronegative surface charge. The presence of $\mathrm{K}^{+}$ or $\mathrm{Na}^{+}$ions $(100 \mathrm{mM})$ prevented the changes of radius and surface charge of the enzyme complex, induced by alteration in ionic strength. It is interesting that the same effect on PDC molecule was observed for $\mathrm{HPO}_{4}{ }^{2-}$ ions, despite differences in charge of $\mathrm{K}^{+}$and $\mathrm{HPO}_{4}{ }^{2}-$ ions. However, these results should be interpreted 


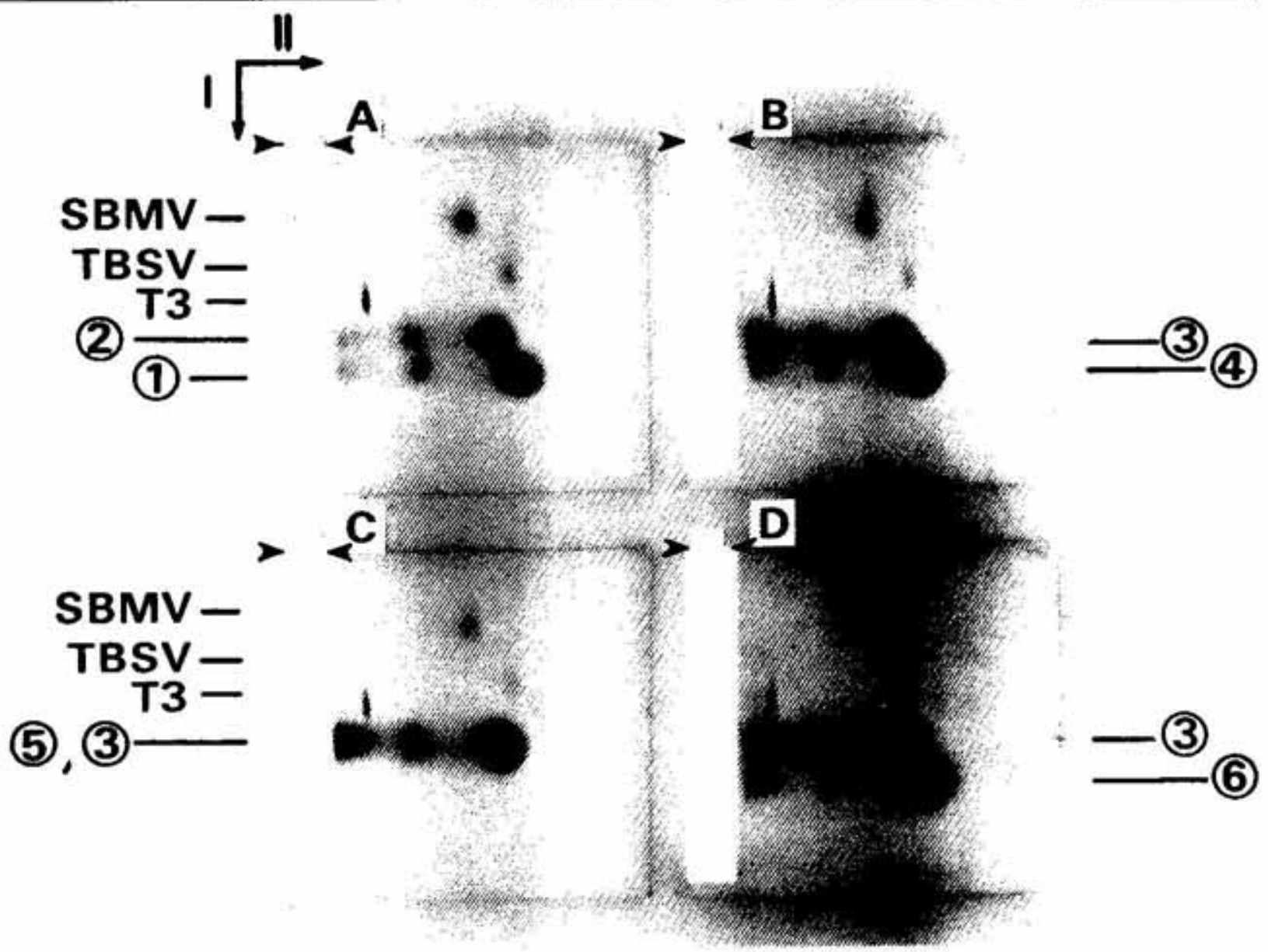

Fig. 3. The effect of $\mathrm{HPO}_{4}{ }^{2-}$ on the size and charge of PDC.

PDC samples were incubated and cross-linked as described in Experimental Procedures at $I=0.04 \mathrm{M}(1) ; I=0.15 \mathrm{M}$ (3);

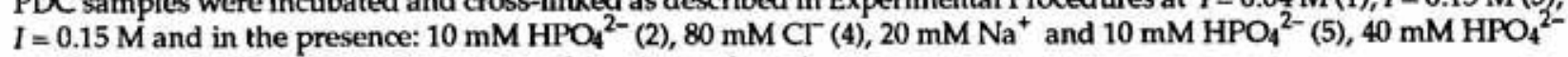
(6). The arrowheads indicate the origins of the electrophoresis.

with caution because glutaraldehyde fixation itself can lead to increased electrophoretic mobility of particles toward the anode [16].

The protein fluorescence is highly sensitive to conformational changes of a protein molecule. There are three intrinsic chromophores in proteins, i.e., phenylalanine, tyrosine and tryptophan residues. Examination of the deduced amino-acid sequences of human PDH $\alpha$ and $\mathrm{PDH} \beta$ indicates that $\mathrm{PDH} \alpha$ possesses 14 phenylalanine, 14 tyrosine and 1 tryptophan residues and $\mathrm{PDH} \beta$ possesses 8 tyrosine, 14 phenylalanine and 5 tryptophan residues [25]. Human dihydrolipoamide acetyltransferase contains 8 tyrosine, 15 phenylalanine and 2 tryptophan residues [26]. Dihydrolipoamide dehydrogenase from human liver contains 15 phenylalanine, 7 tyrosine and 2 tryptophan residues [27]. In proteins that contain all three aromatic amino acids, fluorescence is usually dominated by the contribution of tryptophan residues [28]. The observed small red shift of the maximum fluorescence of PDC accompanying the increase in ionic strength, may indicate that tryptophan residues within the structure of the enzyme complex are more accessible to solvent at high ionic strength. Previously we demonstrated that the activity of $\mathrm{PDC}$ is affected by $\mathrm{Na}^{+}$and $\mathrm{K}^{+}[12,13]$. The stimulatory effect of $\mathrm{Na}^{+}$was mediated only by a change in the $V_{\max }$ of PDC, whereas $\mathrm{K}^{+}$produced an increase in $V_{\max }$ and a change in the Hill coefficient [12]. The results of the present study show that exposition of PDC at constant ionic strength to $\mathrm{K}^{+}$or $\mathrm{Na}^{+}$ions cause respectively, an increase or decrease in the fluorescence intensity (Fig. 5). This observation together with the kinetic data suggest that $\mathrm{K}^{+}$ ions may affect the structure of PDC in a quite different way than does $\mathrm{Na}^{+}$.

The absorption of proteins in the $230-300 \mathrm{~nm}$ range is determined by the aromatic sidechains of tyrosine, tryptophan and phenylalanine. Conformational changes in proteins result in 


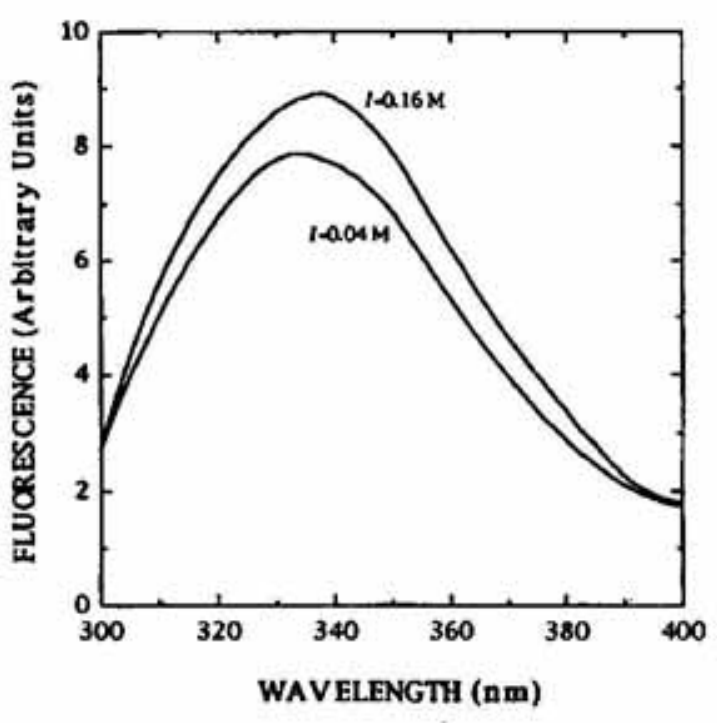

Fig. 4. Changes in the fluorescence emission spectra of PDC induced by variation of ionic strength. $\mathrm{PDC}$ was exposed to Tris/Hepes, $\mathrm{pH} 7.8,1 \mathrm{mM} \mathrm{MgCl} 2$ and ionic strength $I=0.04 \mathrm{M}$ or $I=0.16 \mathrm{M}$, as indicated. The ionic strength of the solutions was standardized to the required value by varying the buffer concentration.

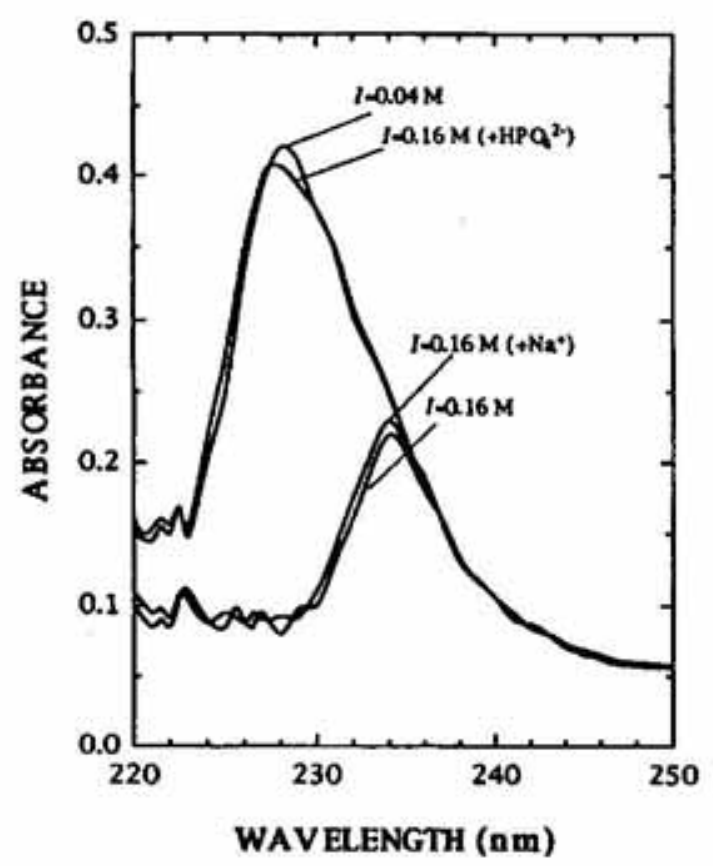

Fig. 6. Changes in the UV spectra of PDC induced by alteration in ionic strength.

$\mathrm{PDC}$ was exposed to Tris/Hepes, $\mathrm{pH} 7.8,1 \mathrm{mM} \mathrm{MgCl} 2$ at the indicated ionic strength and ions. The concentration of $\mathrm{HPO}_{4}{ }^{2-}$ and $\mathrm{Na}^{+}$at $I=0.16 \mathrm{M}$ was 40 and $80 \mathrm{mM}$, respectively. Theionic strength of the solutions wasstandardized to the required value by varying the buffer concentration.

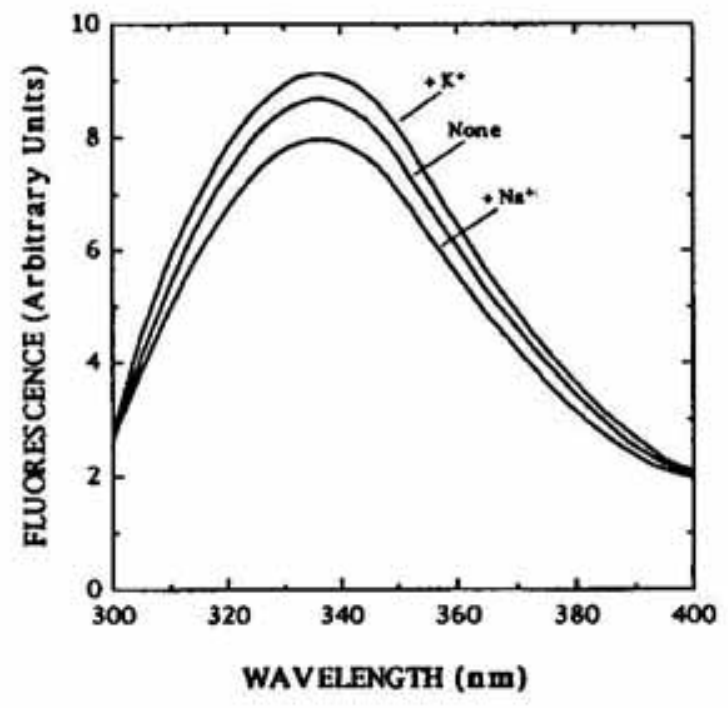

Fig. 5. Changes in the fluorescence emission spectra of $\mathrm{PDC}$ induced by $\mathrm{Na}^{+}$and $\mathrm{K}^{+}$.

$\mathrm{PDC}$ was exposed to Tris/Hepes, $\mathrm{pH} 7.8,1 \mathrm{mM} \mathrm{MgCl} 2$ and $I=0.16 \mathrm{M}$ and $80 \mathrm{mM} \mathrm{K}^{+}$or $\mathrm{Na}^{+}$. The ionic strength of the solutions was standardized to the required value by varying the buffer concentration.

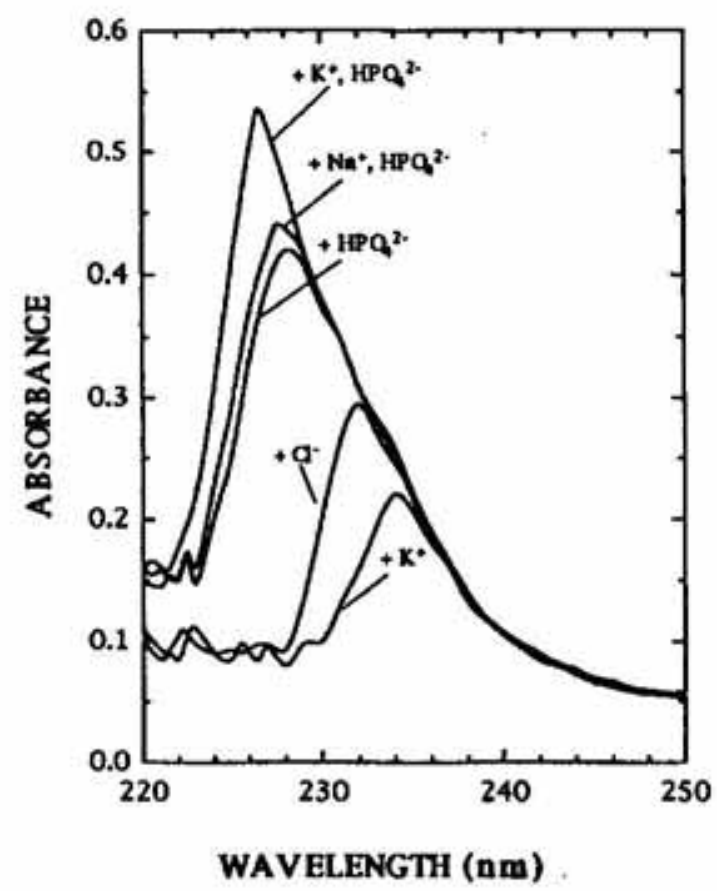

Fig. 7. Changes in the UV specra of PDC induced by mono- and divalent ions.

PDC was exposed to Tris/Hepes, $\mathrm{pH} 7.8,1 \mathrm{mM} \mathrm{MgCl}$, and constant ionic strength $I=0.16 \mathrm{M}$ and the indicated ions at concentration: $\mathrm{HPO}_{4}{ }^{2-}(40 \mathrm{mM}), \mathrm{Na}^{+}(80 \mathrm{mM}), \mathrm{K}^{+}$ $(80 \mathrm{mM}), \mathrm{Cr}^{-}(80 \mathrm{mM})$. The ionic strength of the solutions was standardized to the required value by varying the buffer concentration. 
alterations of absorption in the $220-230 \mathrm{~nm}$ region and may reflect helix-coil transformations in the proteins [29-30]. In addition, changes of protein absorption near $230 \mathrm{~nm}$ may occur due to changes in ionization of the imidazole group of histidine, the thiol group of cysteine or the carboxyl group of tricarboxylic amino acids as it has been reported by several workers [31-33]. These data indicate that changes in protein absorption in the region of $230 \mathrm{~nm}$ can not be attributed to a single phenomenon. The absorption spectra of the aromatic amino acids depend on the nature of the molecular neighbourhood of the respective chromophores. In general, a red shift of the spectrum is observed when the polarity of the molecular neighbourhood is decreased, and a blue shift is observed when its polarity is increased [34]. Thus, the observed decrease in the absorption intensity and a red shift of the absorption peak that accompanied increased ionic strength, may be due to chromophores buried inside the nonpolar part of the enzyme complex molecule. This process could result from the observed changes in surface charge of the enzyme complex and alteration in the PDC radius. The data presented in Fig. 7 indicate that $\mathrm{HPO}_{4}{ }^{2-}$ prevents the absorption changes induced by alteration in ionic strength. Addition of $\mathrm{K}^{+}(80 \mathrm{mM})$ and, to the lesser extent, $\mathrm{Na}^{+}$ in the presence of $40 \mathrm{mMHPO}_{4}{ }^{2-}$ at $0.16 \mathrm{M}$ ionic strength resulted in a higher absorption of PDC in the $230 \mathrm{~nm}$ region, compared to the absorption intensity at $0.04 \mathrm{M}$ ionic strength. It has been shown previously that in the presence of $\mathrm{HPO}_{4}{ }^{2-}, \mathrm{K}^{+}$and $\mathrm{Na}^{+}$exert different effects on the activity of PDC. The presence of $\mathrm{K}^{+}(80$ $\mathrm{mM}$ ) totally prevented the stimulatory effect of $\mathrm{HPO}_{4}{ }^{2-}$, whereas $\mathrm{Na}^{+}(80 \mathrm{mM})$ inhibited the effect of $\mathrm{HPO}_{4}{ }^{2-}$ by $60 \%$ [12].

The data presented in this communication indicate that the ions which influence pyruvate dehydrogenase activity also affect the tertiary and quaternary structure of pyruvate dehydrogenase complex, leading to changes in the environment of the enzyme complex chromophores. The reported effects of anion and cations on PDC may be significant in the kidney, where there is a constant, dynamic, passage of ions across the cells under hormonal regulation. Several previous reports in the literature have shown changes in intracellular ion activities in response to neural and hormonal stimuli [35-38]. Disturbances in acid/base balance which occur during various pathophysiological conditions such as diabetes, starvation or acute and chronic renal insufficiency may cause changes in intracellular $\mathrm{pH}[39,40]$ and redistribution of $\mathrm{K}^{+}$and $\mathrm{Na}^{+}$between the intraand extracellular spaces [41-43]. However, on the basis of reports in the literature of physiological changes in intracellular ion concentrations, it is difficult to estimate the magnitude of such changes in different intracellular spaces, especially in mitochondria. Nevertheless, reports in the literature have shown that intracellular ion heterogeneity is possible $[44,45]$.

\section{REFERENCES}

1. Wieland, O.H. (1983) The mammalian pyruvate dehydrogenase complex: structure and regulation. Rev. Physiol. Biochem. Pharmacol. 96, 123-170.

2. Linn, T.C., Pelley, J.W., Pettit, F.H., Hucho, F., Randall, D.D. \& Reed, L.J. (1972) $\alpha$-Keto acid dehydrogenase complexes. XV. Purification and properties of the component enzymes of the pyruvate dehydrogenase complexes from bovine kidney and heart. Arch. Biochem. Biophys. $148,327-342$.

3. Oliver, R.M. \& Reed, L.J. (1982) Multienzyme complexes; in Electron Microscopy of Proteins (Harris, J.R., ed.) vol 2, pp. 1-48, London, Academic Press.

4. Reed, L.J. \& Hackert, M.L. (1990) Structure-function relationships in dihydro- lipoamide acetyltransferases. J. Biol. Chem. 265, 8971-8974.

5. deMarcucci, O. \& Lindsay, J. (1985) Component $X$ : an immunologically distinct polypeptide associated with mammalian pyruvate dehydrogenase multi-enzyme complex. Eur. J. Biochem. $149,641-648$.

6. Jilka, J.M., Ramatullah, M., Kazemi, M. \& Roche, T.E. (1986) Properties of a newly characterized protein of the bovine kidney pyruvate dehydrogenase complex. J. Biol. Chem. 261, 1858-1867.

7. Pratt, M.L. \& Roche, T.E. (1979) Mechanism of pyruvate inhibition of kidney pyruvate dehydrogenase kinase and synergistic inhibition by pyruvate and ADP. J. Biol. Chem. 254, 7191-7196.

8. Barrera, C.R., Namihira, G., Hamilton, L., Munk, P., Eley, M.H., Linn, T.C. \& Reed, L.J. (1972) $\alpha$-Keto acid dehydrogenase complexes. XVI. Studies on the subunits structure of the pyruvate dehydrogenase complexes from 
bovine kidney and heart. Arch. Biochem. Biophys. 148, 343-358.

9. Patel, M.S. \& Roche, T.E. (1990) Molecular biology and biochemistry of pyruvate dehydrogenase complexes. FASEB J. 4, 3224-3233.

10. Pettit, F.H., Roche, T.E. \& Reed, L.J. (1972) Function of calcium ions in pyruvate dehydrogenase phosphatase activity. Biochem. Biophys. Res. Commun. 49, 563-571.

11. Reed, L.J. \& Olivier, R.M. (1968) The multienzyme $\alpha$-keto acid dehydrogenase complexes. Brookhaven Symp. Biol. 21, 397 - 411.

12. Paweiczyk, T., Easom, R.A. \& Olson, M.S. (1988) The effect of various anions and cations on the regulation of pyruvate dehydrogenase complex from pig kidney cortex. Biochem. J. 253, 819825.

13. Pawelczyk, T., Easom, R.A. \& Olson, M.S. (1992) Effect of ionic strength and $\mathrm{pH}$ on the activity of pyruvate dehydrogenase complex from pig kidney cortex. Arch. Biochem. Biophys. 294, 44-49.

14. Pawelczyk, T. \& Olson, M.S. (1992) Regulation of the pyruvate dehydrogenase kinase activity from pig kidney cortex, Biochem. J. 288, 369-373.

15. Pawełczyk, T. \& Olson, M.S. (1993) The regulatory properties of kidney pyruvate dehydrogenase complex components. Arch. Biochem. Biophys. 300, 489-494.

16. Easom, R.O., DeBuysere, M.S., Olson, M.S. \& Serwer, P. (1989) Size determination of multienzyme complexes using two-dimensional agarose gel electrophoresis. Proteins 5, 224-232.

17. Serwer, P., Hayes, S.J. \& Griess, G.A. (1986) Determination of a particles radius by two-dimensional agarose gel electrophoresis. Anal. Biochem. 152, 339-345.

18. Serwer, P. \& Hayes, S.J. (1986) Exclusion of spheres by agarose gels during agarose gel electrophoresis: Dependence on the spheres radius and the gels concentration. Anal. Biochem. 158, 72-78.

19. Robinson, I.K. \& Harrison, S.C. (1982) Structure of the expanded state of tomato bushy stund virus. Nature (London) 297, 563-568.

20. Abad-Zapatero, C., Abdel-Megiud, S.S., Johnson, J.E., Leslie, A.G.W., Rayment, I., Rossman, M.G., Suck, D. \& Tsukihara, T. (1980) Structure of the southern bean mosaic virus at 2.8 resolution. Nature (London) 286, 33-39.

21. Gornall, A.G., Bardwill, C.J. \& David, M.M. (1949) Determination of serum proteins by means of the biuret reaction. J. Biol. Chem. 177, 751-766.

22. Breslow, F.R.N., Beychok, E.S., Hardman, K.D. \& Gurd, F.R.N. (1965) Relative conformations of sperm whale methyloglobin and apomyoglobin in solution. J. Biol. Chem. 240, 304-309.

23. Shire, S.J., Hanania, G.I.H. \& Gurd, F.R.N. (1974) Electrostatic effects in myoglobin. Hydrogen ion equilibria in sperm whale ferrimyoglobin. Biochemistry 13, 2967-2974.

24. Shire, S.J., Hanania, G.I.H. \& Gurd, F.R.N. (1974) Electrostatic effects in myoglobin. $\mathrm{pH}$ and ionic strength variations of ionization equilibria for individual groups in sperm whale ferrimyoglobin. Biochemistry 13, 2974 - 2979.

25. Koike, K.,Urata, Y. \& Koike, M. (1989) Molecular cloning of $\mathrm{cDNA}$ for $\alpha$ and $\beta$ subunits of human pyruvate dehydrogenase. Ann. N.Y. Acad. Sci. 573, 100-111.

26. Thekkumkara, T.J., Ho, L., Wexler, I.D.,Pons, G., Liu, T.-C. \& Patel, M.S. (1988) Nucleotide sequence of a cDNA for the dihydrolipoamide acetyltransferase of human pyruvate dehydrogenase complex. FEBS Lett. 240, 45-48.

27. Thekkumkara, T.J., Pons, G., Mitroo, S., Jentoft, J.E. \& Patel, M.S. (1989) Molecular biology of the human pyruvate dehydrogenase complex: structural aspects of the $E_{2}$ and $E_{3}$ components. Ann. N.Y. Acad. Sci. 573, 113-129.

28. Brand, L. \& Withold, B. (1967) Methods in Enzymol. 11, 776-856.

29. Glazer, A.N. \& Smith, E.L. (1960) Effect of denaturation on the ultraviolet absorption spectra of protein. J. Biol. Chem. 235, PC43PC44.

30. Glazer, A.N. \& Smith, E.L. (1961) Studies on the ultraviolet difference spectra of proteins and polypeptides. J. Biol. Chem. 236, 2942-2947.

31. Donovan, J.W., Laskowski, M. \& Scheraga, H.A. (1961) The effects of charged groups on the chromophores of lysozyme and of amino acids. J. Am. Chem. Soc. 83, 2686-2694.

32. Benesch, R.E. \& Benesch, R. (1955) The acid strength of the $-\mathrm{SH}$ group in cysteine and related compounds. J. Am. Chem. Soc. 77, 5877-5881.

33. Wetlaufer, D.B. (1962) Ultraviolet spectra of proteins and amino acids; in Advances of Protein Chemistry (Anfinsen, C.B., Jr., Anson, M.L., Bailey, K. \& Edsall, J.T., ed.) vol. 17, pp. 303-390.

34. Donovan, J.W. (1969) Ultraviolet absorption; in Physical principles and techniques of protein chemistry (Sydney J.L., ed.) Part A, pp. 101-169, Academic Press, New York.

35. Baumgarten, C.M., Singer, D.H. \& Fozzard, H. (1984) Intra- and extracellular potassium activities, acetylcholine and resting potential in guinea pig atria. Circ. Res. 54, 65-73. 
36. Wang, W., Messner, G., Oberleithner, H., Lang, F. \& Deetien, P. (1984) The effect of ouabain on intracellular activities of $\mathrm{K}^{+}, \mathrm{Na}^{+}, \mathrm{Cr}^{-}, \mathrm{H}^{+}$, and $\mathrm{Ca}^{2+}$ in proximal tubules of frog kidneys. Pflïgers Arch. 401, 6-13.

37. O'Doherty, J. \& Stark, R.J. (1982) Stimulation of pancreatic acinar secretion: increases in cytosolic calcium and sodium. Am. J. Physiol. 242, G513-G521.

38. Stark, R.J. \& O'Doherty, J. (1982) Intracellular $\mathrm{Na}^{+}$and $\mathrm{K}^{+}$activities during insulin stimulation of rat soleus muscle. Am. J. Physiol. 242, E193-E200.

39. Jones, B. \& Simpson, D.P. (1983) IntracellularpH in intact rat renal cortex estimated with $\left[{ }^{14} \mathrm{C}\right]$ -5,5-dimethyl-2,4-oxazolidimedione. Renal Physiol. 6, 19-27.

40. Jones, B. \& Simpson, D.P. (1983) Influences of alterations in acid-base conditions on intracellular $\mathrm{pH}$ of intact renal cortex. Renal Physiol. 6, 28-35.

41. Mason, J., Beck, F., Dorge, A., Rick, R. \& Thurau, K. (1981) Intracellular electrolyte composition following renal ischemia. Kidney Int. 20, 61-70.

42. Krell, H., Ermisch, N., Kasperek, S. \& Pfaff, E. (1983) On the mechanisms of ATP-induced and succinate-induced redistribution of cations in isolated rat liver cells. Eur. J. Biochem. 131, 247-254.

43. Kubota, T., Biagi, B.A. \& Giebisch, G. (1983) Effects of acid-base disturbances on basolateral membrane potential and intracellular potassium activity in the proximal tubule of Necturus. J. Membrane Biol. 73, 61-68.

44. Beck, F., Bauer, R., Bauer, V., Mason, J., Dorg, A., Rick, R. \& Thurau, K. (1980) Electron microprobe analysis of intracellular elements in the rat kidney. Kidney Int. 17, 756-797.

45. Beck, F., Dorge, A., Rick, R. \& Thurau, K. (1984) Intra- and extracellular element concentrations of rat renal papilla in antidiuresis. Kidney Int. 25, 397-403. 